\title{
ISSR analysis of genetic diversity in sacred lotus cultivars
}

\author{
Yunyun Chen ${ }^{a}$, Renchao Zhou ${ }^{a}$, Xiaodong Lin ${ }^{a}$, \\ Keqiang $\mathrm{Wu}^{\mathrm{b}}$, Xuen Qian ${ }^{\mathrm{c}}$, Shangzhi Huang ${ }^{\mathrm{a}, *}$ \\ ${ }^{a}$ Department of Bioscience, Biotechnology, School of Life Sciences, Sun Yat-sen University, Guangzhou 510275, PR China \\ ${ }^{\mathrm{b}}$ Institute of Plant Biology, College of Life Science, National Taiwan University, Taipei 106, Taiwan \\ ' Sanshui Lotus World, Foshan City, Guangdong 528100, PR China
}

\section{A R T I C L E I N F O}

\section{Article history:}

Received 25 April 2007

Received in revised form 23 December 2007

Accepted 7 March 2008

Available online 14 March 2008

\section{Keywords:}

Nelumbo nucifera

Genetic diversity

ISSR marker

\begin{abstract}
A B S T R A C T
In this study, inter-simple sequence repeats (ISSR) markers were applied to assess genetic diversity and genetic relationships of 92 cultivars of sacred lotus (Nelumbo nucifera Gaertn.), one of the most famous flowers in China. Our results showed that sacred lotus exhibited a low level of genetic diversity (percentage of polymorphic bands, $\mathrm{PPB}=55.8 \%$ ), which may result from its asexual mode of reproduction and long-term artificial selection. Clustering analyses indicated that these cultivars could be divided into two clades. Most cultivars of Chinese lotus species origin were included in one clade, and one cultivar of American lotus species origin was nested in the other clade. The hybrid cultivars from hybridization between the two subspecies were interspersed in these two clades. Seven cultivars native to Thailand formed a distinct subclade among the cultivars of Chinese lotus species origin. Genetic differentiation between two subspecies, and between cultivars from Thailand and other cultivars could be attributed to geographic isolation. The monophyly of three cultivars of Sanshui Winter Lotus and their closest relationships to Chinese lotus species origin suggests that they might have a common origin and may consist completely or mainly of genetic material from $N$. nucifera subsp. nucifera.
\end{abstract}

(c) 2008 Elsevier B.V. All rights reserved.

\section{Introduction}

Nelumbo nucifera Gaertn., also called sacred lotus, is one of the most famous flowers in China. In addition to its ornamental importance, sacred lotus possesses substantial economic importance. The rhizomes and seeds of sacred lotus are consumed worldwide, and its seeds are also used in herbal medicine in China and other countries. In the past, the genus Nelumbo was divided into two species, $N$. nucifera Gaertn., and N. lutea Pers. N. nucifera is distributed throughout Asia and Oceania, with China as its distribution center, while $N$. lutea ranges from North America to the northern South America, with United States as its distribution center (Wang and Zhang, 2004). Despite distinct morphological differences, the two species can hybridize and the offsprings are viable and fertile (Huang et al., 1992; Wang and Zhang, 1999). Therefore, Wang and Zhang (1999) treated them as two subspecies of one species, i.e., $N$. nucifera subsp. nucifera and $N$. nucifera subsp. lutea. We also consider them as two subspecies of the species $N$. nucifera in this study.

\footnotetext{
* Corresponding author. Tel.: +86 20 84036592; fax: +86 2084036215.

E-mail address: huangsz@mail.sysu.edu.cn (S. Huang).
}

Sacred lotus has been cultivated in China for more than 2700 years (Wang and Zhang, 2004). Long artificial hybridization and selection have generated a lot of cultivars of sacred lotus. In China, almost all the cultivars of sacred lotus bloom in the summer, from June to August and begin to wither in September. Recently, three new cultivars ('Donghonghua', 'Xuelihonghua' and 'Aoshuang') have been successfully selected and bred in Sanshui Lotus World, Guangdong, China, which have a long flowering periods of 8 months, from the middle of April to the middle of December. As these cultivars could flower in the winter, they were called as "Sanshui Winter Lotus". Till 2003, more than 600 cultivars of sacred lotus have been recorded (Wang and Zhang, 1999). However, the classification of these cultivars is arbitrary and confusing. Previous scholars have adopted different morphological traits such as flower color, flower shape, flower size, etc., and given these traits different ranks (Ni, 1983; Zou et al., 1997; Wang and Zhang, 1999, 2004). Knowledge of genetic diversity and genetic relatedness among these cultivars is a prerequisite for future breeding and improvement programs. However, it is often hard and even misleading to identify precisely specific cultivars and to infer their origins simply based on the morphological characteristics. Therefore, a further analysis of genetic diversity and genetic relationships of sacred lotus cultivars with molecular means is required. 
Molecular markers such as random amplification of polymorphic DNA (RAPD), inter-simple sequence repeats (ISSR), simple sequence repeats (SSR) and amplified fragment length polymorphism (AFLP) have been successfully used to assess the genetic diversity in cultivars of many plant species (e.g. Balasaravanan et al., 2003; Khan et al., 2005; Martosa et al., 2005; Terzopoulos et al., 2005). ISSR markers overcome the shortcomings of the low reproducibility of RAPD, the high cost of AFLP and the complexity of SSR (Reddy et al., 2002), and represents a fast and a cost-efficient technique. Although the diversity of sacred lotus was explored in the past, most studies used RAPD markers and a very limited number of cultivars were sampled (Zou et al., 1998; Han et al., 2004, 2007a; Guo et al., 2004, 2005, 2007). These studies were discounted because of low reproducibility of RAPD markers. For example, remarkable difference in diversity was observed in the two studies of Guo et al. (2004, 2005), although approximately equal number of cultivars was sampled. Only two studies using ISSR markers focused on wild populations of sacred lotus from northeastern China and central China (Xue et al., 2006; Han et al., 2007b). In this study, we used ISSR markers to systematically assess the genetic diversity and genetic relationships of sacred lotus cultivars. Eighty-nine common cultivars of sacred lotus and three cultivars of "Sanshui Winter Lotus" mentioned above have been included in this study. The objectives of our study were (1) to estimate the genetic diversity of sacred lotus cultivars; (2) to clarify the genetic relationships of these cultivars; (3) to find out genetic affinity of "Sanshui Winter Lotus". Our study would provide useful information for molecular classification and for breeding new cultivars of sacred lotus.

\section{Materials and methods}

\subsection{Plant materials}

Ninety-two sacred lotus cultivars, consisting of 89 common cultivars and 3 "Sanshui Winter Lotus" cultivars were sampled from Sanshui Lotus World, Guangdong, China, during the early summer of 2005. Seven of the 89 cultivars were called Thailand lotus, because they were introduced previously from Thailand. Leaves were collected from two individuals of each cultivar for extracting DNA. These cultivars represent three main types of sacred lotus, namely, the Chinese lotus species origin, $N$. nucifera subsp. lutea species origin (we have used American lotus species origin instead below) and Sino-American hybrid species origin described by Wang and Zhang (2004). There is obvious difference in petal color between cultivars of Chinese lotus species origin and those of American lotus species origin. The petal color is white, red and pink in the Chinese and yellow in the American lotus species. Cultivars of Sino-American hybrid species origin have white, red, yellow and versicolor petals. It is considered that these three types of cultivars are selected and bred from wild $N$. nucifera subsp. nucifera, wild $N$. nucifera subsp. lutea and hybridization between the two subspecies, respectively. Description of cultivars is given by Wang and Zhang (2004).

\subsection{DNA extraction and ISSR-PCR}

DNA extractions were performed from young leaves of each cultivar by the CTAB method (Doyle and Doyle, 1987) with a minor modification. We added PVP in the extraction buffer to eliminate polyphenols in the leaves of sacred lotus. DNA quality and quantity were checked using 1.0\% agarose gel electrophoresis and spectrophotometer, respectively.

The PCR reaction was carried out in $20 \mu \mathrm{L}$ of mixture containing $10 \mathrm{ng}$ of genomic DNA, $2.0 \mathrm{mM} \mathrm{MgCl}_{2}, 0.2 \mathrm{mM}$ dNTP, $10 \times$ buffer (100 mM Tris- $\mathrm{HCl}, \mathrm{pH} 8.0,500 \mathrm{mM} \mathrm{KCl}, 0.8 \%, \mathrm{v} / \mathrm{v}$ NP-40), $1 \mu \mathrm{M}$ primer and 1 U Taq DNA polymerase (Sangon Biological Engineering Technology \& Services Co., Ltd., Shanghai, China). The PCR cycling conditions were as follows: $94{ }^{\circ} \mathrm{C}$ for $5 \mathrm{~min}$ (initial denaturation), then followed by 39 cycles at $94{ }^{\circ} \mathrm{C}$ for $45 \mathrm{~s}$ (denaturation), $55^{\circ} \mathrm{C}$ for $1 \mathrm{~min}$ (annealing), $72^{\circ} \mathrm{C}$ for $2 \mathrm{~min}$ (extension), with a final $8 \mathrm{~min}$ extension at $72{ }^{\circ} \mathrm{C}$ and then a cool down to $4{ }^{\circ} \mathrm{C}$.

One hundred ISSR primers from the Biotechnology Laboratory, University of British Columbia (UBC set no.9) were screened in this study. Twelve ISSR primers that gave clear and polymorphic bands were used in subsequent experiments. The amplifications were repeated twice for each primer analyzed. The PCR products were separated by electrophoresis on $1.5 \%$ agarose gels containing ethidium bromide in a $0.5 \times$ TBE buffer and then photographed under UV light.

\subsection{Data analysis}

The ISSR bands were scored using the binary scoring system that recorded the presence and absence of bands as 1 and 0 , respectively. Typical bands scored were bright and well-separated from other bands, and faint bands were not scored to avoid the scoring of artificial bands. Genetic similarity was calculated on the basis of Jaccard's similarity coefficient (Sneath and Sokal, 1973). The resulting matrix of genetic similarity was used to construct the dendrogram through the unweighted pair group method with arithmetic mean (UPGMA) with the statistical package NTSYS-pc (Rohlf, 1998).

\section{Results}

For 92 sacred lotus cultivars listed in Table 1 , the 12 ISSR primers amplified a total of 138 bands, of which 77 bands were polymorphic. The percentage of polymorphism of the amplified products was $55.8 \%$ (Table 2). The size of amplified bands ranged from approximately 200 to $2000 \mathrm{bp}$. Primer 841 possessed the lowest polymorphism (14.3\%), while primers 827 and 854 showed the highest polymorphism (100\%). The ISSR patterns of 21 cultivars amplified by primer 840 are presented in Fig. 1 .

The UPGMA dendrogram using Jaccard similarity for 92 cultivars was given in Fig. 2. Ninety-two cultivars were grouped into two large clades, A and B. All but one cultivar of Chinese lotus species origin were grouped in Clade A. The only exception was 'Feiyanchunmian' (15), which was grouped in Clade B. Clade B contained one cultivar 'Jinque' (69) from American lotus species origin and several cultivars of Sino-American hybrid species origin. We found that petal colors of the cultivars in Clade B are all yellow or partially yellow. Another cultivar 'Xinghuang' (70) of American lotus species origin was nested in Clade A.

Clade A was further divided into two subclades, A1 and A2. Subclade A1 was composed of seven cultivars native to Thailand. Subclade A2 included some cultivars of Sino-American hybrid species origin, three cultivars of "Sanshui Winter Lotus" and other cultivars of Chinese lotus species origin. A monophyly was formed by these three cultivars of "Sanshui Winter Lotus", among which, 'Donghonghua' (56) and 'Xuelihonghua' (57) were sister cultivars, having the closest genetic relationship. Two cultivars of SinoAmerican hybrid species origin ('Jingcai' (74) and 'Meizhonghong' (81)) and two cultivars of Chinese lotus species origin ('Baiyizhanshi' (14) and 'Ziyulan' (35)), was most closely related to "Sanshui Winter Lotus".

In the dendrogram constructed with ISSR data, the clustering was not consistent with each of the main morphological traits, i.e., plant size, petal patterning and petal color. The cultivars with the same morphological trait like plant size were often placed in different clades or subclades. 
Table 1

Samples of sacred lotus cultivars used in this study

\begin{tabular}{|c|c|c|c|c|c|}
\hline Number & Accession & Origin & Plant size & Petal type & Petal color \\
\hline 1 & Gongxunlian & $\mathrm{C}$ & M & $\mathrm{D}$ & $\mathrm{R}$ \\
\hline 2 & Xinjie & $\mathrm{C}$ & M & $\mathrm{S}$ & W \\
\hline 3 & Shenghuo & $\mathrm{C}$ & M & $\mathrm{D}$ & $\mathrm{R}$ \\
\hline 4 & Saifozuo & $\mathrm{C}$ & M & $\mathrm{D}$ & V \\
\hline 5 & Yizhangqing & $\mathrm{C}$ & M & $\mathrm{F}$ & W \\
\hline 6 & Chengxianbilian & $\mathrm{C}$ & $\mathrm{L}$ & $\mathrm{D}$ & W \\
\hline 7 & Yinqianbiyu & $\mathrm{C}$ & M & $\mathrm{F}$ & $\mathrm{R}$ \\
\hline 8 & Zhongriyouyilian & $\mathrm{C}$ & $\mathrm{L}$ & $\mathrm{F}$ & $\mathrm{R}$ \\
\hline 9 & Taohongsuyu & $\mathrm{C}$ & M & $\mathrm{D}$ & $\mathrm{R}$ \\
\hline 10 & Hongxia & $\mathrm{C}$ & M & $\mathrm{F}$ & $\mathrm{R}$ \\
\hline 11 & Jinghongmudan & $\mathrm{C}$ & M & $\mathrm{D}$ & $\mathrm{R}$ \\
\hline 12 & Fengjuanhongqi & C & $\mathrm{L}$ & $\mathrm{D}$ & $\mathrm{R}$ \\
\hline 13 & Bayilian & $\mathrm{C}$ & $\mathrm{L}$ & $\mathrm{D}$ & $\mathrm{R}$ \\
\hline 14 & Baiyizhanshi & $\mathrm{C}$ & M & $\mathrm{F}$ & W \\
\hline 15 & Feiyanchunmian & $\mathrm{C}$ & M & $\mathrm{S}$ & $P$ \\
\hline 16 & Meiyuanxiuse & $\mathrm{C}$ & M & $\mathrm{S}$ & $\mathrm{R}$ \\
\hline 17 & Tangzhaotisilian & $\mathrm{C}$ & $\mathrm{L}$ & $\mathrm{D}$ & $\mathrm{R}$ \\
\hline 18 & Hongxianglian & $\mathrm{C}$ & $\mathrm{L}$ & $\mathrm{F}$ & $\mathrm{P}$ \\
\hline 19 & Qiancenglian & $\mathrm{C}$ & M & $\mathrm{D}$ & $\mathrm{R}$ \\
\hline 20 & Huoju & $\mathrm{C}$ & M & $\mathrm{D}$ & $\mathrm{R}$ \\
\hline 21 & Xiangbihe & $\mathrm{C}$ & $\mathrm{L}$ & $\mathrm{D}$ & W \\
\hline 22 & Ziyulian & C & M & $\mathrm{D}$ & $\mathrm{R}$ \\
\hline 23 & Liya & $\mathrm{C}$ & M & $\mathrm{D}$ & $\mathrm{P}$ \\
\hline 24 & Zhanhongtu & $\mathrm{C}$ & M & Du & $\mathrm{R}$ \\
\hline 25 & Yinghua & $\mathrm{C}$ & M & $\mathrm{D}$ & $\mathrm{P}$ \\
\hline 26 & Zuichun & $\mathrm{C}$ & M & $\mathrm{Du}$ & $\mathrm{R}$ \\
\hline 27 & Liuyun & $\mathrm{C}$ & $\mathrm{L}$ & $\mathrm{D}$ & W \\
\hline 28 & Tiangaoyundan & $\mathrm{C}$ & M & $\mathrm{D}$ & W \\
\hline 29 & Yanzhilu & $\mathrm{C}$ & M & $\mathrm{Du}$ & $\mathrm{R}$ \\
\hline 30 & Dongfangmingzhu & $\mathrm{C}$ & M & $\mathrm{D}$ & $\mathrm{P}$ \\
\hline 31 & Yanxia & $\mathrm{C}$ & M & $\mathrm{D}$ & $\mathrm{R}$ \\
\hline 32 & Lvyun & $\mathrm{C}$ & M & $\mathrm{D}$ & W \\
\hline 33 & Hongmudan & $\mathrm{C}$ & M & $\mathrm{D}$ & $\mathrm{R}$ \\
\hline 34 & Zhongshanbailian & $\mathrm{C}$ & $\mathrm{L}$ & $\mathrm{D}$ & W \\
\hline 35 & Ziyulan & $\mathrm{C}$ & M & $\mathrm{D}$ & $\mathrm{R}$ \\
\hline 36 & Zhongshanhongtailian & $\mathrm{C}$ & $\mathrm{L}$ & Du & $\mathrm{R}$ \\
\hline 37 & Dasajin & $\mathrm{C}$ & $\mathrm{L}$ & $\mathrm{D}$ & V \\
\hline 38 & Shuangchenyue & $\mathrm{C}$ & M & $\mathrm{D}$ & $\mathrm{P}$ \\
\hline 39 & Zhuoyue & $\mathrm{C}$ & M & $\mathrm{D}$ & $\mathrm{R}$ \\
\hline 40 & Doukounianhua & C & M & Du & $\mathrm{P}$ \\
\hline 41 & Danxiuqiu & $\mathrm{C}$ & M & Du & $\mathrm{R}$ \\
\hline 42 & Baige & $\mathrm{C}$ & M & Du & W \\
\hline 43 & Shuimeiren & $\mathrm{C}$ & M & $\mathrm{Du}$ & $\mathrm{P}$ \\
\hline 44 & Lianxia & $\mathrm{C}$ & M & $\mathrm{S}$ & $\mathrm{R}$ \\
\hline 45 & Hongyandicui & $\mathrm{C}$ & M & $\mathrm{Du}$ & $\mathrm{P}$ \\
\hline 46 & Hongbaoshi & $\mathrm{C}$ & M & Du & $\mathrm{R}$ \\
\hline 47 & Xiaoqu & $\mathrm{C}$ & M & $\mathrm{Du}$ & $\mathrm{P}$ \\
\hline 48 & Hongwanlian & $\mathrm{C}$ & M & $\mathrm{D}$ & V \\
\hline 49 & Lengyanjiaoren & $\mathrm{C}$ & M & $\mathrm{D}$ & V \\
\hline 50 & Xiaozaohong & $\mathrm{C}$ & M & $\mathrm{D}$ & V \\
\hline 51 & Fanxing & $\mathrm{C}$ & M & Du & $\mathrm{P}$ \\
\hline 52 & Honglinglong & $\mathrm{C}$ & M & $\mathrm{Du}$ & $\mathrm{R}$ \\
\hline 53 & Jinzhuluoyupan & $\mathrm{C}$ & M & $\mathrm{F}$ & W \\
\hline 54 & Hongdenglong & $\mathrm{C}$ & M & $\mathrm{D}$ & $\mathrm{R}$ \\
\hline 55 & Xiaojingling & $\mathrm{C}$ & M & $\mathrm{S}$ & $\mathrm{P}$ \\
\hline $56^{a}$ & Donghonghua & $\mathrm{C}$ & $\mathrm{L}$ & $\mathrm{F}$ & $\mathrm{R}$ \\
\hline $57^{a}$ & Xuelihonghua & $\mathrm{C}$ & M & $\mathrm{D}$ & $\mathrm{R}$ \\
\hline $58^{a}$ & Aoshuang & $\mathrm{C}$ & $\mathrm{L}$ & $\mathrm{F}$ & W \\
\hline 59 & Hongtoujin & $\mathrm{C}$ & $\mathrm{L}$ & $\mathrm{F}$ & $\mathrm{R}$ \\
\hline 60 & Taikonglian & $\mathrm{C}$ & $\mathrm{L}$ & $\mathrm{F}$ & $\mathrm{P}$ \\
\hline 61 & Jiangxihonglian & $\mathrm{C}$ & $\mathrm{L}$ & $\mathrm{F}$ & $P$ \\
\hline $62^{b}$ & Huanongying & $\mathrm{C}$ & $\mathrm{L}$ & $\mathrm{F}$ & $P$ \\
\hline $63^{b}$ & Hongshiba & $\mathrm{C}$ & $\mathrm{L}$ & $\mathrm{F}$ & $\mathrm{R}$ \\
\hline $64^{\mathrm{b}}$ & Fenhonglingxiao & $\mathrm{C}$ & $\mathrm{L}$ & $\mathrm{D}$ & $\mathrm{P}$ \\
\hline $65^{b}$ & Yanlijiaren & $\mathrm{C}$ & $\mathrm{L}$ & $\mathrm{D}$ & $\mathrm{R}$ \\
\hline $66^{\mathrm{b}}$ & Zhigaowushang & $\mathrm{C}$ & $\mathrm{L}$ & $\mathrm{D}$ & W \\
\hline $67^{b}$ & Xiaoxue & $\mathrm{C}$ & $\mathrm{L}$ & $\mathrm{F}$ & W \\
\hline $68^{\mathrm{b}}$ & Jiangbei & $\mathrm{C}$ & $\mathrm{L}$ & $\mathrm{F}$ & $\mathrm{R}$ \\
\hline 69 & Jinque & A & M & $\mathrm{F}$ & Y \\
\hline 70 & Xinghuang & A & M & $\mathrm{F}$ & $\mathrm{Y}$ \\
\hline 71 & Zirui & $\mathrm{H}$ & M & Du & $\mathrm{R}$ \\
\hline 72 & Hongtaiyang & $\mathrm{H}$ & M & $\mathrm{D}$ & V \\
\hline 73 & Xinyunjin & $\mathrm{H}$ & M & $\mathrm{D}$ & V \\
\hline 74 & Jingcai & $\mathrm{H}$ & M & $\mathrm{D}$ & V \\
\hline 75 & Huangli & $\mathrm{H}$ & M & $\mathrm{S}$ & $\mathrm{Y}$ \\
\hline
\end{tabular}

Table 1 (Continued)

\begin{tabular}{llllll}
\hline Number & Accession & Origin & Plant size & Petal type & Petal color \\
\hline 76 & Fengwu & H & M & F & V \\
77 & Dicuilian & H & M & S & W \\
78 & Jinbihuihuang & H & M & D & Y \\
79 & Huangmudan & H & M & D & Y \\
80 & Chushuihuangli & H & M & S & Y \\
81 & Meizhonghong & H & M & F & V \\
82 & Bingxinyujie & H & M & D & W \\
83 & Chunxiao & H & M & S & V \\
84 & Huangguan & H & M & D & Y \\
85 & Jinfengzhanchi & H & L & F & Y \\
86 & Honglingjin & H & M & F & R \\
87 & Xiyanghong & H & M & D & V \\
88 & Xiezhao & H & M & S & V \\
89 & Xiangxuehai & H & M & D & Y \\
90 & Yingying & H & M & S & Y \\
91 & Xiaowufei & H & M & F & V \\
92 & Fengcai & H & M & S & V \\
\hline
\end{tabular}

C, Chinese lotus species origin; A, American lotus species origin; $\mathrm{H}$, Sino-American hybrid species origin; L, large-plant size; M, medium-small plant size; F, fewpetalled lotus group; $\mathrm{D}$, double-petalled lotus group; Du, duplicate-petalled lotus group; S, semidouble-petalled lotus group; P, pink-lotus form; W, white-lotus form; $\mathrm{R}$, red-lotus form; Y, yellow-lotus form; V, versicolor-lotus form.

a "Sanshui Winter Lotus".

b Cultivars of sacred lotus from Thailand.

Table 2

Sequences and number of polymorphic bands for each ISSR primers used in this study

\begin{tabular}{llccc}
\hline Primer No. & Sequence $\left(5^{\prime}-3^{\prime}\right)$ & $\begin{array}{l}\text { Number of } \\
\text { amplification } \\
\text { products }\end{array}$ & $\begin{array}{c}\text { Amplification } \\
\text { products, in \% }\end{array}$ \\
\cline { 3 - 5 } & & Total & Polymorphic & \\
\hline 824 & TCT CTC TCT CTC TCT CG & 11 & 2 & 18.2 \\
827 & ACA CAC ACA CAC ACA CG & 16 & 16 & 100.0 \\
834 & AGA GAG AGA GAG AGA GYT & 12 & 5 & 41.7 \\
835 & AGA GAG AGA GAG AGA GYC & 15 & 7 & 46.7 \\
840 & GAG AGA GAG AGA GAG AYT & 14 & 7 & 50.0 \\
841 & GAG AGA GAG AGA GAG AYC & 14 & 2 & 14.3 \\
843 & CTC TCT CTC TCT CTC TRA & 9 & 6 & 66.7 \\
847 & CAC ACA CAC ACA CAC ARC & 5 & 4 & 80.0 \\
852 & TCT CTC TCT CTC TCT CRA & 9 & 6 & 66.7 \\
853 & TCT CTC TCT CTC TCT CRT & 10 & 4 & 40.0 \\
854 & TCT CTC TCT CTC TCT CRG & 4 & 4 & 100.0 \\
856 & ACA CAC ACA CAC ACA CYA & 19 & 14 & 73.7 \\
Total & & 138 & 77 & - \\
Average & & 11.5 & 6.4 & - \\
$\%$ polymorphism & - & - & 55.8 \\
\hline
\end{tabular}

$\mathrm{Y}=(\mathrm{C}, \mathrm{T}) ; \mathrm{R}=(\mathrm{A}, \mathrm{G})$

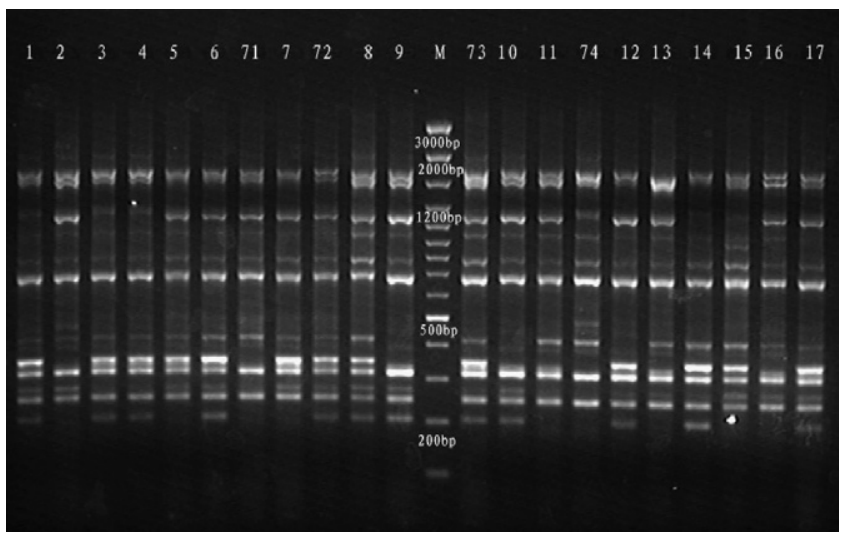

Fig. 1. The ISSR profiles of 21 sacred lotus cultivars obtained by primer 840 (names of cultivars are included in Table 1 ). 


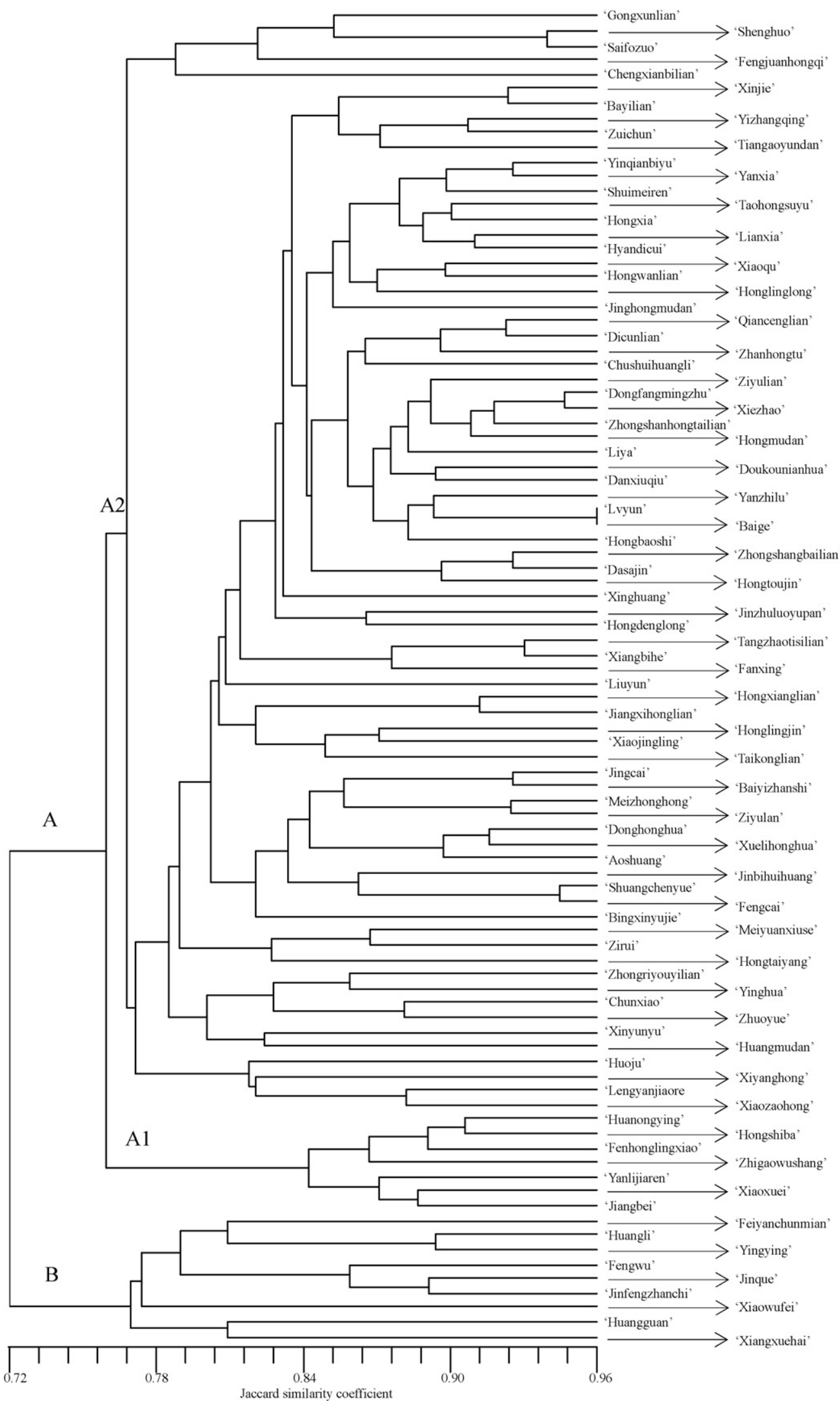

Fig. 2. Dendrogram of 92 cultivars of sacred lotus constructed with UPGMA method. 


\section{Discussion}

\subsection{The genetic diversity of sacred lotus}

In this study, we sampled 92 sacred lotus cultivars, representing three main cultivar types, namely, Chinese lotus species origin, American lotus species origin and Sino-American hybrid species origin. The percentage of polymorphism of the amplified products is $55.8 \%$, which was much lower than that in wild sacred lotus (90.0\%, Han et al., 2007b). There are at least two possible reasons contributing to the low level of genetic diversity in cultivated sacred lotus. On one hand, sacred lotus mainly depends on the rhizomes to propagate in an asexual manner once a new cultivar is selected. This mode of reproduction lacks genetic recombination and thus results in low level of genetic diversity. On the other hand, long-term artificial selection can also reduce the genetic diversity. When people select new cultivars, they usually focus on the forms with high ornamental values, for example, special flower shape and long flowering period, etc. As a result, substantial genetic variation from ancestral gene pool is lost during domestication.

\subsection{Genetic differentiation between two subspecies in Nelumbo}

In our study, nearly all the cultivars of Chinese lotus species origin we examined belong to one clade (A), and one cultivar of American lotus species origin is in the other clade (B). The cultivar 'Jinque' (69) is not grouped into clade B, which may be due to hybridization with another cultivar of Chinese lotus species origin. In our sampling location Sanshui Lotus World, the cultivated pool of 'Jinque' (69) is near to that of Chinese lotus species origin, which may facilitate hybridization mediated by insects (Y. Lu, personal communication). The clear separation between the two clades implies that the two lotus species origins have genetic differentiation to some extent, maybe due to the long-term geographic isolation between Asia and North America. The geographic isolation can also account for the relationship between cultivars from Thailand and others (Fig. 2). Most hybrid cultivars with yellow petals are grouped into American lotus species origin, suggesting that their genetic materials stem predominantly from the subspecies lutea. Considering the genetic differentiation between them revealed in this study, along with the absence of reproductive isolation between them (Huang et al., 1992; Wang and Zhang, 1999), it is reasonable to treat $N$. nucifera and $N$. lutea as two subspecies of the same species.

'Feiyanchunmian' (15) is the only cultivar belonging to Chinese lotus species origin that is nested within Clade $B$, but not within Clade A. We found that most parts of the petals from cultivar 'Feiyanchunmian' (15) are yellow in color, but their top parts are red. This suggests that 'Feiyanchunmian' (15) cultivar is probably a hybrid progeny of two subspecies. It was probably misidentified by Wang and Zhang (2004).

\subsection{The taxonomic status of Sino-American hybrid species origin}

As for the cultivars of Sino-American hybrid species origin, most cultivars with yellow flowers, such as 'Huangli' (75), 'Jinfengzhanchi' (85) and 'Yingying' (90), are grouped into American lotus species origin, whereas most cultivars with red, white or versicolor flowers, such as 'Zirui' (71), 'Bingxinyujie' (82) and 'Meizhonghong' (81), are clustered with Chinese lotus species origin. Therefore, the Sino-American hybrid species origin should not be treated as an independent taxonomic entity. The genetic composition of a hybrid cultivar relies on the ration of genetic materials from two subspecies. If the recurrent parent is subsp. nucifera, it will be close to Chinese lotus species origin, and vice versa. During the longterm cultivation and selection, both artificial and natural hybridization and backcrosses could produce unbalanced genetic components from two subspecies.

\subsection{The classification criteria of Chinese lotus species origin}

According to the classification system of Wang and Zhang (2004) the plants are classified according to plant size, petal patterning and petal color. Firstly, they are classified into largeplant size and mid-small plant size. Secondly, they are classified into few-petalled group, double-petalled group, semidoublepetalled group, duplicate-petalled group and so on. Thirdly, they fall into red-color form, white-color form, pink-color form and versi-color form. In the dendrogram constructed with ISSR data, however, the cultivars could not be clustered according to each of the morphological traits. The mixed distribution of the cultivars with different traits in the dendrogram indicates that plant size, petal patterning and petal color are not the best signature of genetic difference. However, since these morphological criteria such as the plant size, petal shape and petal color are directly associated with their ornamental values, these criteria should be preserved considering the practical principle.

\section{Acknowledgements}

We thank Xingyan Zhang and Qichao Wang (Lotus Flower Research Centre of China) and Suhua Shi (Sun Yat-Sen University) for helpful discussion on the classification of sacred lotus. This study is supported by grants from the National Natural Science Foundation of China (30370912) and Natural Science Foundation of Guangdong Province (04009773, 2006B20101010). The authors thank S. Sawhney for editorial reading of the manuscript and anonymous reviewers for comments and suggestions.

\section{References}

Balasaravanan, T., Pius, P.K., Kumar, R.R., Muraleedharan, N., Shasany, A.K., 2003. Genetic diversity among south Indian tea germplasm (Camellia sinensis, $C$. assamica and C. assamica spp. lasiocalyx) using AFLP markers. Plant Sci. 165, 365-372.

Doyle, J.J., Doyle, J.L., 1987. A rapid DNA isolation procedure for small quantities of fresh leaf tissue. Phytochem. Bulletin 19, 11-15.

Guo, H., Ke, W., Li, S., Peng. J., 2004. Cluster analysis of Nelumbo accessions based on RAPD markers. J. Plant Genet. Res. 5, 328-332.

Guo, H., Li, S., Ke, W., 2005. Genetic diversity and phylogenetic relationship of flower-lotus cultivars (Nelumbo) by RAPD markers. J. Wuhan Bot. Res. 23, 417421.

Guo, H.B., Li, S.M., Peng, J., Ke, W.D., 2007. Genetic diversity of Nelumbo accessions revealed by RAPD. Genet. Resour. Crop. Evol. 54, 741-748.

Han, Y., Zhou, L., Teng, C., Liu, J., Zhou, M., Hu, Z., Song, Y., 2004. Preliminary analysis of DNA polymorphism in lotus (Nelumbo) accessions. Mol. Plant Breed. 2, 380384

Han, Y.-C., Teng, C.-Z., Chang, F.-H., Robert, G.W., Zhou, M.-O., Hu, Z.-L., Song, Y.-C. 2007a. Analyses of genetic relationships in Nelumbo nucifera using nuclear ribosomal ITS sequence data, ISSR and RAPD markers. Aquat. Bot. 87, 141146.

Han, Y.-C., Teng, C.-Z., Zhong, S., Zhou, M.-Q, Hu, Z.-L., Song, Y.-C., 2007b. Genetic variation and clonal diversity in populations of Nelumbo nucifera (Nelumbonaceae) in central China detected by ISSR markers. Aquat. Bot. 86, 69-75.

Huang, X., Chen, J., Huang, G., 1992. Preliminary studies on biosytematic relationship between the two Nelumbo Species. Acta Hortic. Sin. 8, 19-23.

Khan, I.A., Awan, F.S., Ahmad, A., Fu, Y.-B., Iqbal, A., 2005. Genetic diversity of Pakistan wheat germplasm as revealed by RAPD markers. Genet. Res. Crop. Evol. 52, 239-244.

Martosa, V., Royob, C., Rharrabtia, Y., Garcia del Moral, L.F., 2005. Using AFLPs to determine phylogenetic relationships and genetic erosion in durum wheat cultivars released in Italy and Spain throughout the 20th century. Field Crop. Res. 91, 107-116.

Ni, X., 1983. Studies on the classification of Chinese lotus cultivars. Acta Hortic. Sin. $10,207-210$.

Reddy, M.P., Sarla, N., Siddiq, E.A., 2002. Inter simple sequence repeat (ISSR) polymorphism and its application in plant breeding. Euphytica 128, 9-17. 
Rohlf, F.J., 1998. NTSYSpc: Numerical Taxonomy and Multivariate Analysis System, Version 2.02. Exeter Software, Setauket, NY.

Sneath, P.H.A., Sokal, K., 1973. Numerical Taxonomy. WHF, San Francisco.

Terzopoulos, P.J., Kolano, B., Bebeli, P.J., Kaltsikes, P.J., Metzidakis, I., 2005. Identification of Olea europaea L. cultivars using inter-simple sequence repeat markers. Sci. Hortic. 105, 45-51.

Wang, Q., Zhang, X., 1999. Illustrations of Lotus cultivars in China (Continued). China Architecture Industry Press, Beijing.
Wang, Q., Zhang, X., 2004. Illustrations of Lotus cultivars in China. China Forestry Press, Beijing.

Xue, J.K., Zhuo, L.K., Zhou, S.K., 2006. Genetic diversity and geographic pattern of wild lotus (Nelumbo nucifera) in Heilongjiang Province. Chin. Sci. Bull. 51, 421432.

Zou, X., Zhao, X., Jin, X., 1997. Sacred Lotus in China. Jindun Press, Beijing. Zou, Y.P., Cai, M.L., Wang, X., Xu, B.M., 1998. RAPD analysis of germplasm in ancient "Taizi Lotus" and modern Chinese lotus. Acta Bot. Sin. 40, 163-168. 